Archived version from NCDOCKS Institutional Repository http://libres.uncg.edu/ir/asu/

\title{
Appalachľan
}

B O O N E, NORT H CAROLIN A

\section{Reliability Of A Market Basket Assessment Tool (MBAT) For Use In SNAP-Ed Healthy Retail Initiatives}

\author{
By: Sarah A. Misyak, PhD1; Valisa E. Hedrick, PhD, RDN2; Ellen Pudney, MS, RDN1; Elena L. \\ Serrano, PhD1; Alisha R. Farris, PhD, RDN3
}

\begin{abstract}
Objective: To evaluate the reliability of the Market Basket Assessment Tool (MBAT) for assessing the availability of fruits and vegetables, low-fat or nonfat dairy and eggs, lean meats, whole-grain products, and seeds, beans, and nuts in Supplemental Nutrition Assistance Program-authorized retail environments. Methods: Different trained raters used the MBAT simultaneously at 14 retail environments to measure interrater reliability. Raters returned to 12 retail environments $(85.7 \%) 1$ week later to measure test-retest reliability. Data were analyzed using paired-sample $t$ tests and correlations. Results: No significant differences were found for interrater reliability or test-retest reliability for individual categories (mean differences, 0.0 to $0.3 \pm 0.2$ points) or total score (mean difference, $0.5 \pm 0.4$ points and (mean differences, 0.0 to $0.3 \pm 0.3$ points) or total score (mean difference, $0.8 \pm 0.4$ points), respectively. Conclusions and Implications: Future steps include validation of the MBAT. A low-burden tool can facilitate evaluation of efforts to promote healthful foods in retail environments.
\end{abstract}

Misyak, Sarah A. et al. (2018). Reliability of a Market Basket Assessment Tool (MBAT) for Use in SNAP-Ed Healthy Retail Initiatives, Journal of Nutrition Education and Behavior, Volume 50 , Issue $5,511-515$. DOI: https://doi.org/10.1016/i.jneb.2018.01.012. Publisher version of record available at: https://www.jneb.org/article/S1 499-4046(1 8)30041-1/fulltext 


\title{
Reliability of a Market Basket Assessment Tool (MBAT) for Use in SNAP-Ed Healthy Retail Initiatives
}

\author{
Sarah A. Misyak, PhD ${ }^{1}$; Valisa E. Hedrick, PhD, RDN²; Ellen Pudney, MS, RDN'; \\ Elena L. Serrano, $\mathrm{PhD}^{1}$; Alisha R. Farris, PhD, RDN ${ }^{3}$
}

\begin{abstract}
Objective: To evaluate the reliability of the Market Basket Assessment Tool (MBAT) for assessing the availability of fruits and vegetables, low-fat or nonfat dairy and eggs, lean meats, whole-grain products, and seeds, beans, and nuts in Supplemental Nutrition Assistance Program-authorized retail environments. Methods: Different trained raters used the MBAT simultaneously at 14 retail environments to measure interrater reliability. Raters returned to 12 retail environments (85.7\%) 1 week later to measure test-retest reliability. Data were analyzed using paired-sample t tests and correlations.

Results: No significant differences were found for interrater reliability or test-retest reliability for individual categories (mean differences, 0.0 to $0.3 \pm 0.2$ points) or total score (mean difference, $0.5 \pm 0.4$ points and (mean differences, 0.0 to $0.3 \pm 0.3$ points) or total score (mean difference, $0.8 \pm 0.4$ points), respectively. Conclusions and Implications: Future steps include validation of the MBAT. A low-burden tool can facilitate evaluation of efforts to promote healthful foods in retail environments.

Key Words: assessment, reliability, retail nutrition environment, SNAP-Ed, Dietary Guidelines for Americans
\end{abstract}

\section{INTRODUCTION}

The Supplemental Nutrition Assistance Program-Education (SNAP-Ed), which is funded through the US Department of Agriculture's (USDA's) Food and Nutrition Service, is the nutrition education arm of SNAP, the largest government nutrition assistance program in the US. ${ }^{1}$ The goal of SNAPEd is to "improve the likelihood that persons eligible for SNAP will make healthy food choices within a limited budget." 2 The SNAP-Ed operates in all 50 states, Washington DC, and US territories, providing evidence-based nutrition and physical activity direct education and comprehensive, multilevel interventions that include policy, systems, and environmental changes where people eat, live, work, learn, shop, and play.

Many SNAP-Ed-implementing agencies carry out healthy food retail initiatives within the shop setting using SNAP-Ed-endorsed programs as guides (eg, Stock Healthy, Shop Healthy, the Minneapolis Healthy Corner Store Initiative, and the Baltimore Healthy Corner Store Initiative). ${ }^{3-6}$ These efforts generally focus on increasing the availability of healthful foods in food retail outlets

${ }^{1}$ Virginia Cooperative Extension Family Nutrition Program, Department of Human Nutrition, Foods, and Exercise, Virginia Tech, Blacksburg, VA

${ }^{2}$ Department of Human Nutrition, Foods, and Exercise, Virginia Tech, Blacksburg, VA ${ }^{3}$ Department of Nutrition and Health Care Management, Appalachian State University, Boone, $\mathrm{NC}$

Conflict of InterestDisclosure: The authors have not stated any conflicts of interest.

Address for correspondence: Sarah A. Misyak, PhD, Department of Human Nutrition, Foods, and Exercise, College of Agriculture and Life Sciences, Virginia Tech, 333 Wallace Hall, Mail Code 0430, Blacksburg, VA 24061; Phone: (540) 231-8541; Fax: (540) 231-3916; E-mail: smisyak@vt.edu

within local communities. However, storeowners and managers tend to perceive that consumers value convenience over nutritional quality of food items and a higher demand for unhealthy food and beverage items over healthy ones. ${ }^{7-12}$ Researchers and practitioners may experience difficulty convincing store owners to decrease the availability of unhealthy items as part of retail-focused intervention.

Agencies that implement SNAPEd are expected to evaluate and report impacts from their work; therefore, low-cost, low-burden, practical environmental audit measures are needed to assess baseline availability and/or changes based on their efforts. Tools exist that are designed to collect detailed information on the availability and pricing of healthy and unhealthy food items, but information on unhealthy items may be of limited use to researchers and practitioners; it takes significant time and resources to complete such information given store owners and managers' unwillingness to decrease the number of unhealthy food and beverage items that are available.

In an effort to address these current limitations, a simple, lower-burden, standardized evaluation tool was 
created that could be widely used within local and statewide SNAP-Ed retail initiatives. Standardizing the tools used can better inform practice and policy, ${ }^{13}$ particularly as SNAP-Ed continues to move toward standardized evaluation through the SNAP-EdEvaluation Framework. ${ }^{14}$ This newly developed Market Basket Assessment Tool (MBAT), which is available as online Supplementary Data, provides information on the availability and quality of food items that closely align with the 2015-2020 Dietary Guidelines for Americans (DGA) within a variety of retail environments. ${ }^{15}$ Following Townsend's ${ }^{16}$ process for developing reliable, valid, sensitive, and practical measures for SNAP-Ed evaluation, the specific purpose of this study was to investigate the reliability of the MBAT.

\section{METHODS}

\section{Instrument Development}

A team of experts in nutrition, evaluation, SNAP-Ed, and community outreach conducted a review of literature for tools that assess the retail nutrition environment. A score was assigned based on the number of categories of available foods, the number of varieties of foods within those categories, and the quality of available food. Possible total scores ranged from 0 to 40 , with higher scores indicating greater availability, quality, and varieties of items from the different food categories. The scoring structure was developed based on the scoring scheme of an existing audit tool. ${ }^{17}$ Categories included fresh, frozen, and canned fruit and vegetables; lean meat and fish; low-fat and nonfat dairy and eggs; whole-grain products; and dried beans, nuts, and seeds. The MBAT was pilot-tested for 1 year (2015-2016) for face validity in a variety of retail settings and store types including grocery stores, dollar stores, pharmacies, and supercenters. Researchers with expertise in nutrition who were trained in using other environment audit tools assessed the MBAT for the following criteria: level of difficulty or ease of completion, adequate representation of healthy items, and structure and division of food categories on the tool. Based on feedback received, the MBAT was restructured and color-coded to facilitate collecting accurate information; additional food items found to be missing were added within categories; and food categories were subdivided based on fresh, frozen, and canned options.

\section{Procedures}

The researchers recruited SNAP-Ed field staff (extension agents) and undergraduate nutrition students serving as SNAP-Ed interns to serve as raters because of their knowledge of basic nutrition and food resource management principles. The research team initially trained 11 raters to use the MBAT via a video webinar lasting 1-2 hours. After training, raters tested the MBAT. The trained raters then recruited and trained community stakeholders from health-focused community coalitions to serve as raters to test the ease of completion by community practitioners. An additional 6 raters were recruited and trained. Twelve raters participated in interrater reliability testing and 7 participated in test-retest reliability testing. After consultation with Virginia Tech Institutional Review Board staff, it was determined that institutional review board approval was not required for this study because human subjects were not involved, as per US Department of Health and Human Services guidelines, ${ }^{18}$ which state that the Policy for Protection of Human Research Subjects applies only to research involving human subjects.

For interrater reliability testing, 2 trained raters visited a retail outlet at the same time and completed the audit separately (MBAT 1a and 1b. For testretest reliability, a rater completed an in-store assessment (MBAT 1a); then the same rater completed a followup assessment in the same store 1 week later (MBAT 2). Raters were instructed to complete the original assessment (MBAT 1a) and the retest (MBAT 2) on the same day of the week to minimize potential discrepancies owing to store restocking schedules. Stores were unaware of the research study before the store visits, and raters explained their purpose only when questioned by store personnel.

\section{Data Analysis}

Statistical analyses were performed using SPSS statistical software (version
24, IBM, Armonk, NY, 2016). The researchers assessed the MBAT for availability and quality scores for the 6 individual food product categories and for total availability, quality, and overall scores. To evaluate interrater reliability, MBAT scores from 2 trained raters who visited the same outlet on the same day were compared using paired-sample $t$ tests and Pearson bivariate correlations (ie, MBATs 1a and 1b). In addition, an intraclass correlation coefficient (ICC) was assessed to determine interrater reliability for total MBAT scores. Similarly, to assess testretest reliability, MBAT scores measured at the same outlet 1 week apart were compared via paired-sample $t$ tests and Pearson bivariate correlations (ie, MBATs 1a and 2). Significance was set a priori at $P \leq .05$.

\section{RESULTS}

Raters collected data with the MBAT between May and August, 2016 at a convenience sample of 14 SNAPauthorized retail outlets across Virginia, including rural and urban areas and a variety of store types. Data were collected in 4 pharmacies, 5 grocery stores, and 5 dollar stores. Total MBAT scores for all retail outlets ranged from 11 to 40, demonstrating a diverse range of healthy food availability at the audited retail outlets.

\section{Interrater Reliability}

No significant differences were found for responses across MBATs $1 \mathrm{a}$ and $1 \mathrm{~b}$ for individual food product categories (maximum mean difference, $0.3 \pm 0.2$ points) or total MBAT score (mean difference, $0.5 \pm 0.4$ points) between raters on the same day. Moderate to strong correlations were demonstrated across all categories and totals $(r, 0.76-0.99)$ (Table 1$)$. The ICC for the total MBAT score demonstrated excellent agreement for reliability between raters $(\mathrm{ICC}=0.991 ; 95 \%$ confidence interval, 0.974-0.997; $P \leq .001$ ).

\section{Test-Retest Reliability}

Similar to the interrater reliability findings, no significant differences were found for responses in MBATs 1a and 2 for individual food product categories (maximum mean difference, 


\begin{tabular}{lccccc} 
Food Product Categories (Possible Score) & $\begin{array}{c}\text { MBAT 1a } \\
\text { (mean } \pm \text { SD) }\end{array}$ & $\begin{array}{c}\text { MBAT 1b } \\
\text { (mean } \pm \text { SD) }\end{array}$ & $\begin{array}{c}\text { Difference } \\
\text { (Mean } \pm \text { SE) }\end{array}$ & $\begin{array}{c}\boldsymbol{P} \\
\boldsymbol{r}\end{array}$ \\
\hline Grains: total score (0-5) & $3.9 \pm 1.1$ & $3.8 \pm 1.3$ & $0.1 \pm 0.2$ & .75 & .76 \\
\hline Fruit: total score (0-10) & $4.6 \pm 3.9$ & $4.7 \pm 3.8$ & $0.1 \pm 0.1$ & .58 & .99 \\
$\quad$ Availability score (0-7) & $3.6 \pm 2.5$ & $3.6 \pm 2.4$ & $0.1 \pm 0.1$ & .58 & .98 \\
Quality score (0-3) & $1.1 \pm 1.5$ & $1.1 \pm 1.5$ & $0.0 \pm 0.0$ & $\mathrm{~b}$ & $\mathrm{~b}$ \\
Vegetables: total score (0-10) & $5.6 \pm 3.5$ & $5.4 \pm 3.3$ & $0.2 \pm 0.2$ & .39 & .97 \\
$\quad$ Availability score (0-7) & $4.6 \pm 2.1$ & $4.6 \pm 2.1$ & $0.0 \pm 0.1$ & 1.00 & .98 \\
Quality score (0-3) & $1.1 \pm 1.5$ & $0.9 \pm 1.4$ & $0.2 \pm 0.2$ & .34 & .85 \\
Meat: total score (0-4) & $2.8 \pm 1.2$ & $2.7 \pm 1.2$ & $0.1 \pm 0.1$ & .34 & .98 \\
$\quad$ Availability score (0-4) & $2.8 \pm 1.2$ & $2.7 \pm 1.2$ & $0.1 \pm 0.1$ & .34 & .98 \\
Quality score (-1 to 0) & $0.0 \pm 0.0$ & $0.0 \pm 0.0$ & $0.0 \pm 0.0$ & $\mathrm{~b}$ & $\mathrm{~b}$ \\
Dairy and eggs: total (0-5) & $3.7 \pm 1.4$ & $3.4 \pm 1.4$ & $0.3 \pm 0.2$ & .10 & .91 \\
$\quad$ Availability score (0-5) & $3.7 \pm 1.4$ & $3.4 \pm 1.4$ & $0.3 \pm 0.2$ & .10 & .91 \\
Quality score (-1 to 0) & $0.0 \pm 0.0$ & $0.0 \pm 0.0$ & $0.0 \pm 0.0$ & $\mathrm{~b}$ & $\mathrm{~b}$ \\
Dried beans, seeds, nuts, and nut butters: total score (0-6) & $5.6 \pm 0.8$ & $5.6 \pm 0.6$ & $0.1 \pm 0.1$ & .58 & .78 \\
\hline Total MBAT score (0-40) & $26.2 \pm 10.8$ & $25.7 \pm 10.4$ & $0.5 \pm 0.4$ & .19 & .99 \\
$\quad$ Total availability score (0-34) & $24.1 \pm 8.0$ & $23.8 \pm 7.9$ & $0.3 \pm 0.3$ & .37 & .99 \\
Total quality score (0-6) & $2.1 \pm 3.0$ & $1.9 \pm 2.8$ & $0.2 \pm 0.2$ & .34 & .96 \\
\hline
\end{tabular}

aMean differences according to paired-sample $t$ test; slight differences may be noted from the preceding columns owing to rounding; ${ }^{\mathrm{b} T}$ The correlation cannot be computed because the SE of the difference is 0 .

Note: Interrater reliability was assessed by comparing responses from 2 trained raters who visited the same outlet on the same day. MBAT 1a reflects responses from first interrater audits and $1 \mathrm{~b}$ reflects responses from second interrater audits).

Pearson correlations are presented.

$0.3 \pm 0.3$ points) or total MBAT score (mean difference, $0.8 \pm 0.4$ points) over 1 week. Moderate to strong correlations were demonstrated across all categories and totals $(r, 0.74-0.99)$ (Table 2$)$.

\section{DISCUSSION}

The MBAT was developed as a retail environment audit tool for use by SNAP-Ed-implementing agencies to evaluate healthy food availability and affordability in SNAP-authorized retail outlets for multiple store types used by SNAP shoppers. Results showed the MBAT to be reliable in terms of interrater and test-retest reliability, because the strength of all correlations were above the acceptable limits of $0.5-0.7 \cdot{ }^{16,19}$ This tool can help to fill a gap in currently available tools to assess the retail food environment.

A recent review of environmental measures of food retail outlets by
Glanz et $\mathrm{al}^{13}$ identified the Nutrition Environment Measures Survey for Stores (NEMS-S) and a food store survey developed by the USDA Food Assistance and Nutrition Research Program, using the USDA's Thrifty Food Plan (TFP) as a framework, as the most widely used tools for auditing stores. ${ }^{20}$ The NEMS-S has historically been considered the reference standard for auditing food retail outlet environments because of its availability to researchers and determined reliability. Although the NEMS-S is a useful tool for comparing healthy and unhealthy food products within that environment, it may be burdensome for some researchers and communitylevel practitioners in that it requires an extensive amount of time for training (around 9 hours for the entire NEMS-S training), data collection, data cleaning, and analysis. In addition, different adaptations of the NEMS-Smust be used in separate retail environment types, ${ }^{17}$ which makes direct comparisons and standardization difficult across different types of retail settings.

The USDA food store survey can be used to assess availability and affordability in retail outlets based on the TFP. ${ }^{21}$ This tool provides a standardized method for collecting information on available food variety, whether foods are affordable for SNAP participants and other low-income households, and whether the foods making up a TFP market basket can be purchased at a given retail location. ${ }^{21}$ Unfortunately, this tool includes information on food items that are not promoted for consumption by lowincome individuals and families through SNAP-Ed programming (eg, margarine, sugar, pancake syrup, chocolate drink mix) and was not tested for reliability. Information from the MBAT can be compared with the external 
Test-Retest Reliability ( $n=12$ Pairs)

\begin{tabular}{|c|c|c|c|c|c|}
\hline Food Product Categories (Possible Score) & $\begin{array}{c}\text { MBAT 1a } \\
(\text { mean } \pm \text { SD })\end{array}$ & $\begin{array}{c}\text { MBAT } 2 \\
(\text { mean } \pm \text { SD })\end{array}$ & $\begin{array}{c}\text { Difference } \\
(\text { mean } \pm \text { SE })^{\mathrm{a}}\end{array}$ & $P$ & $r$ \\
\hline Grains: total score (0-5) & $3.8 \pm 1.1$ & $4.1 \pm 0.9$ & $0.3 \pm 0.2$ & .28 & .74 \\
\hline Fruit: total score (0-10) & $4.3 \pm 3.9$ & $4.6 \pm 3.6$ & $0.3 \pm 0.3$ & .34 & .98 \\
\hline Availability score (0-7) & $3.3 \pm 2.6$ & $3.6 \pm 2.2$ & $0.3 \pm 0.3$ & .34 & .95 \\
\hline Quality score (0-3) & $1.0 \pm 1.5$ & $1.0 \pm 1.5$ & $0.0 \pm 0.0$ & $\mathrm{~b}$ & $\mathrm{~b}$ \\
\hline Vegetables: total score (0-10) & $5.3 \pm 3.6$ & $5.5 \pm 3.5$ & $0.2 \pm 0.1$ & .17 & .99 \\
\hline Availability score $(0-7)$ & $4.3 \pm 2.2$ & $4.5 \pm 2.2$ & $0.2 \pm 0.1$ & .17 & .98 \\
\hline Quality score (0-3) & $1.0 \pm 1.5$ & $1.0 \pm 1.5$ & $0.0 \pm 0.0$ & $\mathrm{~b}$ & b \\
\hline Meat: total score $(0-4)$ & $2.8 \pm 1.2$ & $2.7 \pm 1.3$ & $0.1 \pm 0.1$ & .34 & .98 \\
\hline Availability score (0-4) & $2.8 \pm 1.2$ & $2.7 \pm 1.3$ & $0.1 \pm 0.1$ & .34 & .98 \\
\hline Quality score (-1 to 0 ) & $0.0 \pm 0.0$ & $0.0 \pm 0.0$ & $0.0 \pm 0.0$ & $\mathrm{~b}$ & $\mathrm{~b}$ \\
\hline Dairy and eggs: total (0-5) & $3.8 \pm 1.3$ & $4.0 \pm 1.3$ & $0.2 \pm 0.2$ & .34 & .90 \\
\hline Availability score (0-5) & $3.8 \pm 1.3$ & $4.0 \pm 1.3$ & $0.2 \pm 0.2$ & .34 & .90 \\
\hline Quality score (-1 to 0) & $0.0 \pm 0.0$ & $0.0 \pm 0.0$ & $0.0 \pm 0.0$ & b & b \\
\hline Dried beans, seeds, nuts, and nut butters: total score (0-6) & $5.5 \pm 0.8$ & $5.6 \pm 0.7$ & $0.1 \pm 0.1$ & .59 & .77 \\
\hline Total MBAT score $(0-40)$ & $25.6 \pm 10.9$ & $26.4 \pm 10.2$ & $0.8 \pm 0.4$ & .06 & .99 \\
\hline Total availability score (0-34) & $23.6 \pm 8.2$ & $24.4 \pm 7.5$ & $0.8 \pm 0.4$ & .06 & .99 \\
\hline Total quality score (0-6) & $2.0 \pm 3.0$ & $2.0 \pm 3.0$ & $0.0 \pm 0.0$ & $\mathrm{~b}$ & b \\
\hline
\end{tabular}

aMean differences according to paired-sample t test; slight differences may be noted from the preceding columns owing to rounding. ${ }^{b}$ The correlation cannot be computed because the SE of the difference is 0 .

Note: Test-retest reliability was assessed by comparing responses from 2 different time points at the same outlet (MBATs $1 \mathrm{a}$ and 2) (MBAT $1 \mathrm{a}$ reflects responses from the first audit and $1 \mathrm{~b}$ reflects responses from the second audit). Pearson correlations are presented.

standard of the TFP, but it eliminates the need to collect information on items not promoted for consumption by SNAP-Ed based on the DGA.

Despite the tool's strengths, SNAP-

Ed implementing agencies should consider its scope before using it, because the MBAT was developed to assess healthy food availability in retail environments. Therefore, it does not include beverages besides low-fat or nonfat milk, and thus data on sugarsweetened beverages cannot be collected. In addition, the tool does not assess snack foods (eg, granola bars) owing to the difficulty of setting guidelines for what constitutes a healthy snack. Unlike the NEMS-S, the MBAT does not allow for price comparison of healthy and unhealthy foods in store and the price does not factor into scores. However, data can be compared across multiple outlet types within communities and used to assess the availability and price of foods against the external standard of the TFP.

Another limitation is that retests all occurred 1 week after the original test. It is unclear whether test-retest reliability would be affected by longer intervals between tests owing to a variety of variables such as seasonality, availability of items, and employee turnover. Another limitation is the relatively small sample size of stores from a single state, which may have affected generalizability of the findings.

\section{IMPLICATIONS FOR RESEARCH AND PRACTICE}

The MBAT has the potential to decrease burden on SNAP-Ed-implementing agencies and community practitioners conducting needs assessments or evaluating programs to improve food retail environments. Completion time will be assessed with validity testing; however, the associated assessment time is hypothesized to be muchlower because the MBAT is 4 pages long, compared with the NEMS$\mathrm{S}$, which is 15 pages long. The MBAT may be useful for assessing regional and geographic differences in healthy food availability. This tool was developed for SNAP-Ed programs to encourage the use of a standardized evaluation of initiatives to promote healthy food purchases in retail, which would allow for aggregation of results to show the impact of SNAP-Ed on retail environments nationwide.

Ongoing and future research includes testing of the MBAT in a larger number of retail settings and in other locations across the country toensure 
generalizability, testing the reliability of the MBAT in corner and convenience stores, finalizing validity testing, and assessing for instrument sensitivity. A guide to completing a market basket analysis using data collected through the MBAT is also under development for use by SNAP-Ed programs. Adoption of the MBAT by SNAP-Ed-implementing agencies and different community organizations will also be assessed.

The MBAT can document changes in real and perceived availability of healthy food items after interventions and programs. Future research and programming focusing on strategies to sustain increased perceived and real availability of healthy items that align with the DGA is warranted. These initiatives must be acceptable to store owners and managers, and be sustainable from a business perspective.

\section{ACKNOWLEDGMENTS}

This work was partially funded by SNAPEd, the USDA, Food and NutritionService, and by overhead funding from the Department of Human Nutrition, Foods, and Exercise at Virginia Tech.

\section{SUPPLEMENTARY DATA}

Supplementary data related to this article can be found at https://doi.org/ 10.1016/j.jneb.2018.01.012.

\section{REFERENCES}

1. US Department of Agriculture. Supplemental Nutrition Assistance Program Education. https://www.fns.usda.gov/ snap/supplemental-nutrition-assistanceprogram-education-snap-ed. Accessed May 5, 2017.

2. US Department of Agriculture. Supplemental Nutrition Assistance Program Education Nutrition Plan Guidance FY 2018. USDA Food and Nutrition Service. https://snaped.fns.usda.gov/ administration/snap-ed-plan-guidanceand-templates. Accessed July 13, 2017.

3. Missouri Extension. Stock Healthy, Shop Healthy. http://extension.missouri.edu/ stockhealthy/home.aspx. Accessed May 12, 2017.

4. Gittelsohn J, Suratkar S, Song HJ, et al. Process evaluation of Baltimore Healthy Stores: a pilot health intervention program with supermarkets and corner stores in Baltimore City. Health Promot Pract. 2010;11:723-732.

5. City of Minneapolis Health Department. Testing an Evaluation Model for Assessing the Efficacy of the Minneapolis Healthy Corner Store Program. Minneapolis, MN: City of Minneapolis Health Department; 2013.

6. US Department of Agriculture. SNAP-Ed Toolkit: obesity prevention interventions and evaluation framework. https://snapedtoolkit.org/. Accessed July 13, 2017.

7. Andreyeva T, Middleton AE, Long MW, Luedicke J, Schwartz MB. Food retailer practices, attitudes and beliefs about the supply of healthy foods. Public Health Nutr. 2013;14:1024-1031.

8. O’Malley K, Gustat J, Rice J, Johnson CC. Feasibility of increasing access to healthy foods in neighborhood corner stores. J Community Health. 2013;38: 741-749.

9. Abarca J, Ramachandran S. Using community indicators to assess nutrition in Arizona-Mexico border communities. Prev Chronic Dis. 2005;2:A06.

10. Sanchez-Flack JC, Baquero B, Linnan LA, Gittelsohn J, Pickrel JL, Ayala GX. What influences Latino grocery shopping behavior? Perspectives on the small food store environment from managers and employees in San Diego, California. Ecol Food Nutr. 2016;55:163181.

11. Song HJ, Gittelsohn J, Kim M, Suratkar S, Sharma S, Anliker J. Korean American storeowners' perceived barriers and motivators for implementing a corner store-based program. Health Promot Pract. 2011;12:472-482.

12. Wingert K, Zachary DA, Fox M, Gittelsohn J, Surkan PJ. Child as change agent: the potential of children to increase healthy food purchasing. Appetite. 2014;81:330-336.

13. Glanz K, Johnson L, Yaroch AL, Phillips M, Ayala GX, Davis EL. Measures of retail food store environments and sales: review and implications for healthy eating initiatives. J Nutr Educ Behav. 2016; 48:280-288, e281.

14. USDA Food and Nutrition Service. The Supplemental Nutrition Assistance Program Education (SNAP-Ed) Evaluation Framework: Nutrition, Physical Activity, and Obesity Prevention Indicators: Interpretive Guide to the SNAP-Ed Evaluation Framework. 2016. https://snaped.fns.usda.gov/ snap/EvaluationFramework/SNAP -EdEvaluationFrameworkInterpretive Guide.pdf. Accessed May 5, 2017.

15. US Department of Health and Human Services and US Department of Agriculture. 2015-2020 Dietary Guidelines for Americans. Washington, DC: US Department of Health and Human Services and US Department of Agriculture; 2015.

16. Townsend MS. Evaluating food stamp nutrition education: process for development and validation of evaluation measures. J Nutr Educ Behav. 2006;38: 18-24.

17. GlanzK, Sallis JF, Saelens BE, FrankLD. Nutrition Environment Measures Survey in stores (NEMS-S): development and evaluation. Am J Prev Med. 2007;32: 282-289.

18. Subpart A, Basic HHS. Policy for Protection of Human Research Subjects, 45 CFR 46, §46.101; 1991. https:/ /www .hhs.gov/ohrp/regulations-and-policy/ regulations/45-cfr-46/index.html. Accessed January 12, 2018.

19. Willet WC. Nutritional Epidemiology. 3rd ed. New York, NY: Oxford University Press; 2013.

20. Carlson A, Lino M, Juan WY, Hanson K, Basiotis PP. Thrifty Food Plan, 2006. USDA Center for Nutrition Policy and Promotion; 2007. CNPP-19. https:// www.cnpp.usda.gov/sites/default/ files/usda_food_plans_cost_of_food/ TFP2006Report.pdf. Accessed May 5, 2017.

21. Cohen B, Andrews M, Scott Kantor L. Community Food Security Assessment Toolkit. 2002. EFAN-02-013. https:// www.ers.usda.gov/publications/pub -details $/$ ?pubid=43179. Accessed July 14, 2017. 